\title{
A perspectiva da invenção numa pesquisa em educação: processos e aprendizagens de um pesquisar-inventivo.
}

\begin{abstract}
Resumo
Estes escritos compõem a trajetória de um encontro entre uma pesquisa em educação e a temática da invenção, de Virgínia Kastrup. Trata de percorrer o processo dessa pesquisa e a relação da invenção, os processos de subjetivação e a formação de professores. A perspectiva cognitiva da invenção é a da invenção de problemas e implica um constante movimento de problematização, de afetar-se pela novidade e pela surpresa, potencializando-se na possibilidade e capacidade do vivo de problematizar, de eliminar o determinismo que a recognição impõe. Com base nisso, encontros com futuros professores foram pensados dentro de um espaço formativo: provocações, colocações de problemas, forças que permitissem rupturas recognitivas, afecção, estranhamento ao que chegava de diferencial e problemático. Uma pesquisa que se fez num movimento incessante de idas e vindas, no próprio processo de aprender outro campo de possibilidades de pensar, de criar, de sentir, e de viver.
\end{abstract}

Palavras-chave: invenção, problematização, pesquisa em educação, aprendizagem, processualidade

The perspective of invention in research in Education:

processes and learning of an inventive-research

\begin{abstract}
These writings constitute the trajectory of an encounter between a research in Education and Virgínia Kastrup's thematic of invention. They are about going through the process of this research and the relation of invention, the processes of subjectification and teachers' formation. The cognitive perspective of invention is the one of problem invention and implies a constant movement of problematization, of getting affected by novelty and surprise, potentialized in the possibility and capability of the living problematizing, eliminating the determinism which recognition imposes. Based on this, meetings with pre-service teachers were considered within a formative space: provokations, problem posing, forces which allow recognitive ruptures, affection, strangeness to what appear different and problematic. A research which was done in an unceasing movement of comings and goings, in the process of learning another field of possibilities for thinking, creating, feeling, and living.
\end{abstract}

Keywords: invention, problematization, research in Education, learning, processuality 


\section{Do encontro com o problema}

Estes escritos são compostos por fragmentos de uma pesquisa de mestrado no campo da educação, realizado nos anos de 2011 e 2012. Sob o olhar da temática da invenção, da autora Virgínia Kastrup (2007a), traçaram-se modos, um "como" pensar uma pesquisa sob a perspectiva da invenção, dentro de um espaço de formação inicial de professores. O nome cunhado posteriormente de Encontros, foram movimentos construídos neste espaço, com base em uma perspectiva inventiva da cognição e que, através do olhar cartográfico, a pesquisa se fazia, em linhas incertas e moduláveis.

Nesta perspectiva, abre-se campo para a liberdade de contar um percurso, quando aberta efetivamente para a invenção de problemas na pesquisa, e não resolução dos mesmos. Ao longo desse processo, vou trazendo ao leitor alguns caminhos, escolhas, e o delineamento de instalação de paralisias e inquietações, onde então a pesquisa tomava outros rumos e construía suas direções divergentes, indo, voltando, e remanejando os traçados.

A invenção está atrelada, neste artigo, à aprendizagem. Ambos são processos correlativos. E para explicar propriamente a invenção, com base em Virgínia Kastrup, trago alguns pontos que me levaram, na construção da pesquisa, à temática do aprender. Transitarei por várias vozes, porque se trata sempre de um percurso coletivo, e que, na construção de uma escrita, aparecem em conjugações verbais diversas, ou seja, não somente em primeira.

Virgínia Kastrup $(2000 ; 2001 ; 2003 ; 2004 ; 2005 a ; 2005 b ; 2007 b)$ e seu universo de problematizações que giram em torno da invenção passaram a ser o objeto de estudo logo no início da pesquisa de mestrado. A temática, complexa e ampla, remexia no vivido em sala de aula e nos espaços da universidade, suscitando uma mistura de admiração e angústia no encontro com as teorizações e, principalmente, do que esse encontro tencionava a pensar, na pertinência da perspectiva inventiva da cognição e seu enfoque na aprendizagem, por solicitar novas maneiras de estar no mundo. Na composição das linhas que se entrelaçam para se chegar efetivamente ao tema da pesquisa, durante a construção da escrita da dissertação em si, fiz questão de trazer durante o trabalho os caminhos que me levavam aos nós de intersecção de conceitos e produção dos Encontros num espaço de formação de professores. Foram os escritos de Kastrup que me encaminharam às tantas vozes com quem me relacionei no trabalho e no que queria abordar de início: a relação entre a invenção, os processos de subjetivação e a formação de professores. 
Do que se trata a invenção? De acordo com a autora, invenção é problematização: é certa abertura, indeterminismo e inacabamento das operações cognitivas. Foram em seus estudos epistemológicos da cognição que ela traçou a perspectiva de uma psicologia da invenção como algo inexistente. Com seu olhar na atualidade, e saindo do âmbito do discurso psicológico vigente, que a invenção aparece em seu caráter problemático (sob diversas formulações, ela aparece em estudos de Ilya Prigogine, Isabel Stengers, Gilles Deleuze e Félix Guattari, Henri Bergson, Frederich Nietzsche, entre outros) e que é possível constatar a ausência de seu tratamento pela psicologia. Determinada por seu projeto epistemológico - o qual se encontra enraizado na modernidade -, a psicologia atual entende a cognição como espaço de representação, ou seja, concebida unicamente como espaço intermediário entre sujeito e objeto, já pré-dados. O conhecimento situa-se entre dois pólos, não só distintos, mas separados, "sem que seja considerada a possibilidade de produção de efeitos recíprocos" (KASTRUP, 2007a, p. 50). Ele não produz nada dessa relação, apenas representa, reconhece (ou seja, o objeto está pronto, acabado, e nós - através de uma cognição invariante, que funciona dentro de leis científicas universais - o reconhecemos). Se a cognição invaria, explica a autora, a invenção torna-se um problema inexistente, pois o sistema cognitivo não está sujeito a surpresas, abalos, transformações, fenômenos nos quais a invenção é possível.

Para compreender melhor a determinação desse projeto epistemológico, Kastrup constrói a própria constituição da modernidade. Conforme a autora, e sua análise sustentada em Foucault, a psicologia cognitiva (bem como toda ciência moderna) configurou e efetivou seu projeto no desenvolvimento apoiado em uma das vertentes da modernidade: a analítica da verdade. Vertente onde se situam as "filosofias pós-kantianas que trabalham sobre o tema do conhecimento, considerando a existência de limites que não podem ser ultrapassados" (2007a, p. 22). O movimento instituído pela analítica da verdade é o mesmo que operou de forma direta na constituição da psicologia cognitiva. A mesma, buscando as condições da cognição, institucionalizou a orientação da ciência moderna, entendendo a cognição como invariante, protegida dos efeitos da prática cognitiva, acrescentando a ela limites inultrapassáveis. O que escapava desses limites, que ultrapassava ao campo dos invariantes e que apontava para o funcionamento de outras vias da cognição, surge como um resíduo, algo recalcado, esquecido pela psicologia: o tempo. É essa dimensão temporal - o resto da constituição da psicologia cognitiva explicitada - que Kastrup, então, procura trazer para que a invenção seja pensada.

$\mathrm{Na}$ ontologia do presente, a outra vertente da modernidade, Kastrup buscou a crítica de todas as categorias que não variam, aplicando o tempo a elas. O tempo, sob a perspectiva desta vertente - onde as filosofias o tomam "como algo que constitui a substância mesma do real que, nesse caso, é sempre passível de transformação, de 
redefinição e de ultrapassamento de seus limites" (KASTRUP, 2007a, p. 22) -, é onde a invenção poderá ser problematizada. Tempo-conceito trabalhado pela autora e denominado de diversas formas pelos teóricos os quais ela utiliza: perturbações, breakdowns, afecções, devires.

O que implicava o contato com a perspectiva da invenção e que produzia ressonâncias no lugar de pesquisadora em educação? De que não somos centros inventores, sujeitos psicológicos que inventam; a invenção surge justamente desse fundo temporal, que nos impede de distinguir e delimitar sujeito e objeto. Sujeito e objetos tornam-se abalados em seu caráter apriorístico, como algo pré-instituído, subsistindo apenas como efeitos da inventividade. Invenção, assim, não se define como um processo psicológico a mais (além da percepção, do pensamento, da aprendizagem, da memória ou da linguagem) e sim como potência: potência de diferenciação, potência temporal, força que atravessa todos os processos psicológicos (KASTRUP, 2005a). Tem-se aí uma cognição que é intrinsicamente inventiva - em suas condições de possibilidade, transformação, processualidade - e também inventada, pois inventar é dar lugar a novas formas, novas e imprevisíveis.

Na perspectiva de uma cognição inventiva e inventada podemos falar da produção de novas subjetividades. Subjetividade aqui está atrelada a ideia de produção, produção de formas de sensibilidade, de pensamento, de desejo, de ação. Ela não é um dado, um ponto fixo, nem mesmo uma origem. Tampouco se confunde assim com um sujeito, como um domínio de referências próprias do mesmo. É a partir de um campo de subjetivação, um campo de processos que, o que costumamos chamar de sujeito, se constitui. Esse campo é constituído por saberes e coisas, de ordens estéticas, politicas, linguísticas, tecnológicas, econômicas, que se atravessam e que mudam a todo momento, constituindo também os "objetos" e que, portanto, também nunca estão dados, prontos: "sujeitos e objetos emergem desse fundo, de uma rede de limites indefinidos, em constante processo de transformação de si mesma" (KASTRUP, 2007a, p. 205). Do processo de inventar e do invento, nós temos o processo de produção de subjetividades e de seu produto: somos o invento de nós mesmos.

Chamava-me atenção, à época dos primeiros encontros com a problemática, a ideia de que podemos encarnar o funcionamento inventivo quando operamos através de uma política inventiva, exercitando a problematização, afetando-se pela novidade trazida pela experiência presente e tomando o conhecimento como invenção de si e do mundo. Da mesma forma a nossa relação com o aprender: fazer a cognição diferenciar-se permanentemente de si, não submetendo a aprendizagem a seus resultados, mas abrindo a possibilidade da continuidade da operação da cognição às experiências nãorecognitivas e ao devir. Entretanto, como acrescenta a autora, o desafio de operar por 
um política inventiva é "conceber práticas que viabilizem o desencadeamento de processos de problematização que não se esgotem ao encontrar uma solução" (KASTRUP, 2005a, p.1282). Ficava claro esse desejo de inventar enquanto micropolítica, vivendo numa relação com o mundo em que ele não está pré-estabelecido, mas que inventamos ao viver, lidando com o que nos chega e nos atinge. Isso é produção de si, produção de um mundo, produção de novas e infinitas formas de conhecer e de viver.

Era isso o que movimentava a pesquisa, em suas primeiras fundamentações: uma invenção como algo a ser produzido, desencadeado, operado como micropolítica. O que se produziu disso?

\section{O aprender da invenção: experiências de problematização}

Foi do estranhamento com o tema e com a inquietação que ele produzia que basicamente a pesquisa mesma ia se constituindo, atrelada de perguntas, de vazios, névoas conceituas. Para poder construí-la e, minimamente, produzir neste contexto, achei necessário compartilhar o enfoque do conceito cunhado pela autora de aprendizagem inventiva e a questão da atenção em sala de aula.

A partir dos estudos da invenção, Kastrup traz um novo entendimento de aprendizagem e de uma relação com o aprender, quando pensada não apenas como um processo de solução de problemas - que influi diretamente na capacidade do estudante, por exemplo, prestar atenção para a realização de tarefas em sala de aula -, mas também como invenção de problemas, invenção de novas relações e novos modos de vida. A perspectiva cognitiva da invenção de problemas implica um constante movimento de problematização, de afetar-se pela novidade e pela surpresa, implicando uma cognição que não se esgota na simples repetição e na procura de soluções de hipóteses préconcebidas. A cognição, assim, se potencializa na possibilidade e capacidade do humano de problematizar e, na sua atividade inventiva, eliminar o determinismo que a recognição impõe. A aprendizagem a partir da invenção abre espaço para a produção de novas subjetividades, reconfigurações do mundo, sendo, portanto, interna a nós, e não externa, unicamente.

Aprender como um processo inconcluso, aberto, dinâmico e incerto: é, sobretudo, inventar problemas, viver experiências de problematização. Neste tipo de experiência, faculdades mentais como sensibilidade, memória, imaginação e atenção divergem, atuam em caminhos diferentes, estranham-se e incitam o movimento do aprender. Ampliava-se o conceito de atenção, situada no ato de prestar atenção a tarefas, objetos ou situações externas, para uma atenção que se constitui variável, modulada, que 
desliza do foco para outros campos, podendo ser um ato de encontro com experiências pré-simbólicas e de invenção de problemas (KASTRUP, 2000; DE-NARDIN e SORDI, 2007).

Mas vamos além. Quando a autora se refere a estas experiências de problematização, que chama igualmente de experiências de estranhamento - afirma que estas se revelam através de breakdowns (Varela 1992 apud KASTRUP, 2007a) que, por sua vez, constituem perturbações, rupturas no fluxo cognitivo habitual, certa descontinuidade no processo cognitivo. Trata-se

de uma atividade caótica, de oscilações sinápticas muito rápidas, que precedem a formação dos agregados funcionais de neurônios, correlatos à estabilização da experiência (percepção, hábito etc.), e que respondem pela recognição, ou como prefere Varela, pelos estados de prontidão cognitiva (KASTRUP, 2007a, p. 151).

É um movimento que potencializa o nascimento do novo, compondo um diálogo entre uma situação específica vivida e a capacidade do sujeito exercer ações apropriadas "que respondem pelos estados de prontidão cognitiva". Esta noção de breakdown procura mostrar o enraizamento da cognição no concreto, desconstruindo seu funcionamento apenas do ponto de vista da lógica, dos mecanismos gerais previsíveis e em equilíbrio, da representação. Breakdown percebido como problematização cognitiva é realização de uma atividade que acontece no presente imediato e é nesse presente que o concreto vive, na ação, na vida prática, sempre, portanto, inventando-se.

Essa espécie de hesitação que constitui o breakdown é o que foge dos esquemas recognitivos:

Tomo como exemplo a experiência, bastante comum, embora não banal, de alguém que retorna, anos mais tarde, à casa onde morou durante a infância. Não raro, tem lugar então uma experiência cognitiva que não é mero reconhecimento. O reconhecimento mistura-se a um estranhamento acerca das dimensões da casa. 0 imenso quintal lhe parece agora um pequeno pátio, a antiga escada não passa de alguns degraus, o portão, embora o mesmo, revela-se outro. A perplexidade experimentada suscita, e mesmo impõe, a invenção de uma outra cognição da casa. Eis um exemplo de uma experiência em que a cognição funciona como problematização dos esquemas da recognição. O que a distingue é o fato de referir-se a algo que tem o paradoxal estatuto de familiar e, ao mesmo tempo, estranho. Por isso, é um tipo de experiência de problematização: intriga, faz pensar, força a invenção (KASTRUP, 2007a, p. 69).

A experiência de um mergulho no vivido é a existência de uma atenção que não se confunde com aquela com que nós realizamos nossas atividades da vida cotidiana. É uma oscilação natural, independente de um esforço consciente e que permite ao sujeito uma volta à experiência, "impregnado de lembranças que atuam no momento atual, 
possibilitando-Ihe uma vivência de conexão entre passado e presente, desde onde se torna possível a invenção" (SORDI e DE-NARDIN, 2009, p. 84).

A distração - corriqueiramente tão indesejada no meio escolar quando nos pegamos afirmando que "o aluno é distraído, não presta atenção nas aulas" - é justamente esse vaguear da atenção, onde ele experimenta uma errância que vai na direção de um campo mais amplo. E, por isso, no contato com essa perspectiva do aprender, era-me inevitável não voltar à sala de aula, oscilando entre o desejo de estar lá de novo e fazer diferente do que tinha feito até então, e correr, para bem longe de qualquer instituição de ensino, acreditando não saber lidar com a potência inventiva de qualquer ente. Martelavam indagações de como se poderia ampliar essa potência temporal da invenção. E assim as questões se faziam: por que então não falar disso com futuros professores? Criar espaços de discussão onde poderia colocá-los frente a esta temática (e que, portanto, modificaria suas compreensões de invenção e aprendizagem)? Nos entremeios da pesquisa e dessas inquietações é que então já percebia que a aprendizagem já estava se dando, porque ela, afinal, começa quando não reconhecemos, mas ao contrário, estranhamos, problematizamos.

\section{E quando, então, a arte serviu de referência...}

Dentro da discussão da aprendizagem inventiva, por compartilhamentos de experiências de problematização, entrava em contato, também a partir de Kastrup e de certo aprofundamento em Deleuze, com a aprendizagem de signos, outros meandros de conceitos de aprender, ainda tão tímidos no meio educacional:

Deleuze $[\ldots]$ afirma que aprender é considerar uma matéria ou objeto como se estes emitissem signos a serem decifrados. Aprender marcenaria é ser sensível aos signos da madeira; aprender medicina é ser sensível aos signos da doença; aprender a cozinhar é ser sensível aos odores, às cores, às texturas dos ingredientes da comida; aprender a jogar futebol é ser sensível aos signos da bola, do campo, da torcida, dos jogadores. Poderíamos multiplicar os exemplos, mas no momento basta sublinhar que tudo que nos ensina alguma coisa emite signos, e não se aprende senão por decifração e interpretação (KASTRUP, 2001, p. 20).

Os signos nos interpelam, nos chegam, possuem uma força que nos coloca a pensar, exercendo em nós uma ação direta, sem utilizar da representação. É o plano de produção de subjetividades que é acionado no processo de aprendizagem. Subjetividade constituída por múltiplas linhas e planos de forças que atuam ao mesmo tempo. Linhas duras (plano do visível ou molar), que é da ordem da forma, da consciência, das representações (que detêm a divisão binária de sexo, profissão, camada social, e que 
sempre classificam, decodificam os sujeitos) e do imaginário; e linhas flexíveis (plano do invisível ou molecular) em que não existe ordem, estrutura, identidade, modelo, mas sim fluxos, segundo os movimentos do desejo, que buscam constituir máscaras, engendrando diferentes formas (RAMÃO et al., 2005). São essas linhas flexíveis, que possibilitam o afetamento da subjetividade pelas relações e encontros efetuados, pela intersecção com o "fora" que forma um agenciamento, as chamadas linhas de fuga (ROMAGNOLI, 2009).

Este fora que nos chega, quando tocado pelos signos que emite - e que pela diferença que este fora potencialmente porta, produz linhas de fuga -, provoca uma experiência de problematização, de invenção de problema. Então, "só a partir daí ocorre a busca de solução e de sentido. Ao acaso dos encontros segue-se a necessidade imposta pelo que nos força a pensar. Aprendemos por coação, forçados pelos signos, ao acaso dos encontros" (KASTRUP, 2001, p. 20).

Mas, e por que a arte serve de referência? Porque colocar o problema da aprendizagem do ponto de vista da arte é colocá-lo do ponto de vista da invenção. Para Deleuze (2006), toda obra de arte revela uma essência: sendo ela mesma diferença, última e absoluta. Somente a arte, "no que diz respeito à manifestação das essências, é capaz de nos dar o que procurávamos em vão na vida" (p. 39). Os signos da vida, das viagens, do amor, - como coloca Deleuze em sua análise de Proust - não portam esta diversidade, essa diferença que a obra de arte, em essência, porta. E como a essência se encarna na obra de arte? Nas matérias: a cor para o pintor, o som para o músico e a palavra para o escritor. Mas não confundamos essência com o objeto, pois a arte é uma verdadeira transmutação da matéria, importando apenas "os temas inconscientes, os arquétipos involuntários, dos quais as palavras, como as cores e os sons, tiram o seu sentido e a sua vida" (p. 45). Ou seja, os signos da arte possuem uma superioridade em relação aos demais. Por serem potência de diferenciação, permitem que se estendam e se imponham nas formas perceptivas do viver. Emitem signos capazes de serem retroativos nas nossas vidas, fazendo parte de um ponto de vista. Ponto de vista que não será de um sujeito ou de um objeto, mas o da diferença e o da invenção que potencialmente a arte abarca.

Quando acionados pelo que nos chega, fugimos da recognição que nos mantém sempre conectados às coisas. O termo breakdown tomava a cena novamente, para explicar essa espécie de quebra, de rachadura no fluxo cognitivo habitual, os estranhamentos, as experiências de problematização, já trazidas anteriormente.

A experiência estética, por exemplo, é um ponto onde ocorrem essas experiências de problematização, de invenção de problemas e aprendizagem por signos. A partir de um encontro com os signos das artes, igualmente há uma quebra recognitiva - experiência 
de breakdown, afecção, devir - que produz movimentos de alterização. Isso pode gerar um encontro, onde acessamos o plano de forças moventes, no encontro com intensidades. A experiência literária, por exemplo, aciona o leitor a experiências de estranhamento e problematização, num plano pré-subjetivo. Isso é encontro com as forças de alteridade que habitam o leitor (CABRAL E KASTRUP, 2006).

Nesse sentido, é importante salientar que, percebendo como a arte age sobre nossos modos de existência - não sendo ela um alvo, mas um "atrator caótico, um ponto que é tendencial, sem ser fixo e sem possibilitar falar em regimes estáveis ou em resultados previsíveis" (KASTRUP, 2001, p. 19), talvez pudéssemos aprender a operarmos como atratores caóticos permitindo, a si e aos que nos rodeiam, colocar-se com outro olhar frente à perspectiva do aprender, relacionando-nos sob o ponto de vista do estranhamento e da problematização. Foram por estes olhares que a pesquisa percorria.

Entretanto, não se desejava falar sobre aprendizagem inventiva com futuros professores, do dizer a alguém o que se devia fazer e como fazer uma possível aprendizagem inventiva, porque tampouco sabíamos sobre isso. Era um equívoco teorizá-la como algo a ser feito, instigado, induzido. A questão era justamente deixar de conceber o conceito de invenção pelo senso-comum, ou seja, como um processo específico da propriedade cognitiva de artistas ou mesmo de cientistas, algo que pertence a uma genialidade. 0 interesse era pensar a inventividade que produz o nosso cotidiano e que permeia o funcionamento cognitivo de todos nós. Era o problema da aprendizagem inventiva sob o ponto de vista da arte que era desejada de ser sentida num espaço formativo. A arte aparecendo enquanto uma maneira de operar e expor o problema do aprender auxiliava a entendê-la no lugar de problema, no entendimento de que toda aprendizagem começa com a invenção de problemas. Era o que se estava inventando (e aprendendo), devidamente, como um processo de construção de uma pesquisa em educação.

\section{De leituras, sons e imagens: travessias}

Então, no encontro com o conceito de experiência de problematização, e de suas extensões, foi que pensei em movimentar um espaço formativo. Permaneci com as perguntas que me motivaram e potencializaram meu encontro com a temática de início: Que problematizações permitem o processo da cognição inventiva? O que pode o espaço formativo que permita uma atenção necessária à invenção (experiências de breakdown que invente novas formas de ser e estar no mundo, de produção de subjetividades)? Como abrir campo para experiências de uma atenção necessária à invenção (abertura ao desconhecido, às afeções, ao devir)? Eram questionamentos que me empurravam para 
uma exigência igualmente de invenção: de pensamento, de criação de um outro corpo, de outros movimento de vida, em meio à vida. E a escrita, então, se fez ela mesma o material do artista que produz, colocando-se na paisagem do que acontecia, chegando, emergindo e inventando-se, deixando ser ela mesma a inscrição de uma outra pesquisadora. Os Encontros pensados com os alunos estavam aí, no meio.

Através da Disciplina de Docência Orientada I do curso de Mestrado em Educação da UFSM, interviemos na disciplina de estágios supervisionados I do ensino médio do curso de licenciatura em Ciências Biológicas, no primeiro semestre de 2011. Em um primeiro momento, havia o desejo de encontros que circulassem pelo acontecimento da surpresa/experiência estética. De provocações, colocações de problemas, de imposição de forças que permitissem rupturas recognitivas, afecção, estranhamento ao que chegava de diferencial e problemático. Desejo de lançar percursos desterritorializantes, buscarmos outros territórios existenciais, diferentes formas de nos percebermos no mundo, criando um espaço formativo diferente do habitual no âmbito dos estágios. No escuro, na inventividade da nossa própria investigação, nosso objetivo foi mexer com as estruturas institucionais a ponto de nos desfazermos de nossos aventais brancos, nem que seja momentaneamente, nem que sejam aqueles invisíveis que carregamos na mente, na linguagem (GUATTARI, 1990) e em nossas maneiras de estar no mundo.

Nos escritos com experiências a partir de textos literários (KASTRUP, 2005b; CABRAL, 2006; CABRAL E KASTRUP, 2009), passei a encontrar meios de experimentar outros espaços e tempos formativos. Textos literários transformam-se numa figura de potência problematizadora que, em sua prática, abrem campo para a experiência inventiva. Para encarar a leitura como estranhamento, no entanto, é preciso investir nesse processo de desconstruir a concepção de cognição unicamente como representação, em que a leitura habitualmente surge e efetua-se apenas enquanto compreensão e interpretação literal do texto.

Abertura com o que lemos e do que, a partir disso, nos move; as forças que estabelecemos com o texto e a fruição das mesmas. Em que medida essa relação de abertura e acolhimento com o texto, estranha e nos transforma, a ponto de abalar o que está constituído? Essa leitura envolve uma quebra na recognição (breakdown, devires, afecção) - as experiências de surpresa e estranhamento -, promovido pelo texto, redirecionando a atenção externa para uma atenção interna. Uma leitura onde experimentamos certo tempo vazio, um gesto de acolhimento, caracterizado por uma atenção que acolhe, aberto para "si mesmo" e para o mundo, receptivo e disposto ao que pode reverberar. São estas etapas em conjunto que promovem, o que as autoras 
denominam, de evidência intuitiva, onde alguma coisa que habitava-nos, e do qual não tínhamos ciência, surge, se produz, e já não somos mais os mesmos.

Pensava em fazê-los experimentar, abrir campo para esse sensível do pensamento. Da possibilidade de leitura de textos literários, produzir "alguma coisa", sem garantias de coisa alguma. Mover perguntas, mais do que fornecer respostas. Tratava-se de compartilhar de momentos de atenção a si, de uma atenção que se passa no momento presente, no que acontece naquele instante, e que é dirigida à experiência em ato.

Levar livros de diversos gêneros literários para o primeiro encontro surgiu com as leituras de acolhimento e mais particularmente do devir consciente em rodas de poesia. Rendia-me à proposta de "utilizar a poesia para suscitar experiências de estranhamento e surpresa, para colocar o leitor em contato com sua dimensão pré-subjetiva e processual, aquém do indivíduo, promovendo um encontro com a alteridade que habita a subjetividade" (KASTRUP, 2005b, p. 53).

Na roda, e com ajuda de coordenadores, Kastrup relata que a poesia era lida em voz alta e, dessa leitura, ao produzir experiência de estranhamento comentado ao grupo, outras experiências eram suscitadas, que extrapolavam o que era trazido pelo poema lido. A conversa que ia surgindo na roda fazia surgir um plano coletivo, onde falas de um grupo heterogêneo ampliavam a figura da cognição dada como algo individual. Falas que suscitavam outras falas, concorrendo para a emergência de outras experiências de devir. Kastrup nos encaminha a visualizar a questão da roda de leitura como uma figura da cognição coletiva como transformação de si e de produção de subjetividades.

Dessas suas experimentações, pensei a proposta de um encontro com a leitura, mas não somente de poesia: juntei crônicas, prosas, contos, fragmentos de romances e fiz eles aglomerarem-se num espaço. Fixei-me na força da leitura em voz alta suscitar algo no outro (e em quem lê), das experiências que, quando narradas, expandissem, multiplicassem o sentido do texto lido de acordo com o que afeta, estranha. A cada fragmento de textos que selecionava de livros que haviam sido lidos por mim outrora na vida, pensava se poderia afetá-los. E por aí segui.

Brincava também, embalada pela ideia da experiência estética, em usar música. Experiência musical/sonora que, a partir da escuta de poesias narradas, músicas, ou crônicas, pudessem produzir parecidos movimentos que a leitura pode provocar. Brincar com as palavras, jogar entre elas. Parar para escutar, silenciar e sentir a musicalidadepoema. O que produzem enquanto sensação?

$E$, na construção do último encontro, trabalhara com algumas colocações de Deleuze, em suas análises referentes às obras de Francis Bacon, em que seus escritos provocavam o 
desejo de brincar com a sensação. Sensação como vibração, sendo ela mesma violenta, que age diretamente sobre nosso sistema nervoso. Da violência promovida por uma força:

é preciso que uma força se exerça sobre um corpo, ou seja, sobre um ponto da onda, para que haja sensação. Mas se a força é a condição da sensação, não é ela, contudo, que é sentida, pois a sensação "dá" outra coisa bem diferente a partir das forças que a condicionam. É assim que a música deve tornar sonoras forças insonoras, e a pintura, visíveis forças invisíveis (DELEUZE, 2007, p. $62)$.

Nesse sentido, nenhuma arte é figurativa, cabendo a ela a tentativa de tornar visíveis forças que não são visíveis. Estendera aquilo para uma imagem, pensando talvez que, em uma imagem fotográfica - ou mesmo na literatura e na música -, história alguma poderia ser narrada/ilustrada quando se tratava de captar as forças que emanam. Por isso, optei em esconder descrições de imagens selecionadas, legendas contidas em fotos da Série Êxodos, de Sebastião Salgado. No entanto, sabemos que as imagens de Sebastião traz uma história, uma narrativa, a memória de algo. Por isso, se queria fugir momentaneamente de perspectivas representativas, e lidar com a invenção, por que usar estas imagens?

Porque as imagens me inquietavam. Meu encontro com elas não era meramente representativo, por isso usei delas, mesmo sabendo que o encontro dos estudantes com as imagens não seria o mesmo. Dos nosso desejos: abalar, inquietar, desejo de desestabilizar, produzir outras vias de pensamento. Foram estes desejos que conduziram o trabalho a certas configurações, mesmo sabendo de certo cuidado que temos que ter, ao procurar problematizar espaços e tempos de aprender, para não levantar bandeiras e acabar caindo em certa moralização, sobressaindo outros valores. Esses desejos e escolhas da pesquisa não a reduzem nem a determinam, mas certamente conduziu o trabalho a certas configurações, e não a outras.

Outro aspecto importante de brevemente salientar diz respeito ao registro que acompanhava a investigação. A todo momento indagava-me em como olhar para o que queríamos traçar. Tateando, havia a constante tentativa de produzirmos alguma coisa com os alunos naquele espaço, "alguma coisa" que somente o desenrolar do percurso produziria. Neste tateio, encontramos - e nos perdemos constantemente - a cartografia:

o termo 'cartografia' utiliza especificidades da geografia para criar relações de diferença entre 'territórios' e dar conta de um 'espaço'. Assim, 'cartografia' é um termo que faz referência à ideia de 'mapa', contrapondo à topologia quantitativa, que categoriza o terreno de forma estática e extensa, uma outra de cunho dinâmico, que procura capturar intensidades, ou seja, disponível ao registro do acompanhamento das transformações decorridas no 
terreno percorrido e à implicação do sujeito percebedor do mundo cartografado (KIRST et al., 2003, p. 92).

Portanto, se falamos de um espaço, de um tempo, de processos e de aprender a inventar problemas (e não solucioná-los), o caminho cartográfico parecia se apresentar pertinente por constituir uma ferramenta de investigação que abarca a complexidade, colocando problemas, traçando o coletivo de forças das situações, evitando categorizações e reducionismos (ROMAGNOLI, 2009). Diferentemente de outros caminhos metodológicos e em contraposição à separação entre sujeito e objeto, a cartografia "convoca a imanência, a exterioridade das forças que atuam na realidade, buscando conexões, abrindo-se para o que afeta a subjetividade" (p. 169). Através dela, percebemos que não cabe ao trabalho estabelecer um caminho linear para atingir um fim. Tratava-se de acompanhar um processo, e não representar um objeto.

Com ela passamos a pensar sobre outra via de produzir conhecimento, modo que envolve "a criação, a arte, a implicação do autor, artista, pesquisador, cartógrafo" (MAIRESSE, 2003, p. 259). Procuramos inventar (e aprender): um espaço, um tempo, um lugar de encontro, em que o fim dos encontros não indicasse o fechamento de um processo. Por isso, todas as produções que emergiram naqueles espaços e tempos serviram e continuam servindo como guia e fontes de compreensão do processo da pesquisa. Enquanto cartografia, o que nos interessa é o registro dos encontros compartilhados, capturando "no tempo o instante do encontro dos movimentos do pesquisador com os movimentos do território de pesquisa" (KIRST et al., 2003, p. 100), aprendendo a explorar, interpretar e produzir com os achados dos signos que ocuparam aquele tempo e espaço.

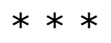

\section{Um pouco dos Encontros ${ }^{1}$}

No primeiro encontro, entreguei-Ihes seus diários. Disse-Ihes que não precisavam colocar nomes e que podiam utilizá-lo a qualquer tempo e lugar. Pedira-Ihes que anotassem o que fossem encontrando na leitura, no manuseio do livro que escolheriam, e que elegessem - entre os fragmentos que havia selecionado por livro (um conto inteiro, poesia, prosa, ou partes de um romance) - a parte que quisessem para ler em voz alta ao grupo. Nos diários, explicara que gostaria que prestassem atenção à leitura e

\footnotetext{
${ }^{1}$ Definimos Encontros a partir da leitura espinosista deste conceito, no encontro entre os corpos, trazida por Deleuze. Aprendi mais com esse conceito nos últimos meses da pesquisa, onde me deixei levar sem tanto medo nas velocidades das composições que fui fazendo com o mundo. Trago aqui o que colabora no trabalho, sobre esse corpo que se deseja construir no contato com as coisas, que se modula e se faz ao sabor dos próprios encontros: "De um lado, um corpo, por menor que seja, sempre comporta uma infinidade de partículas: são as relações de repouso e de movimento, de velocidades e de lentidões entre partículas que definem um corpo, a individualidade de um corpo. De outro lado, um corpo que afeta outros corpos, ou é afetado por outros corpos: é este poder de afetar e de ser afetado que também define um corpo na sua individualidade" (DELEUZE, 2002, p. 128).
} 
escrevessem o que eles acolhiam do que liam, o que mexia/desacomodava/agradava do que estavam lendo. Este movimento foi sempre, a cada encontro, rememorado, nos encontros com as músicas/crônicas faladas e também com as imagens.

Percorrer gravações e diários demoradamente. Ao longo de repetidas e sucessivas escutas e leituras, passamos a desconfigurarmo-nos, na necessidade do distanciamento da escuta, e de estar sempre refazendo a escrita, cortando aqui, brotando lá, deixando que ela corra com decisão e leveza. Pensar que construímos parcerias - os corpos que passam por nós e que inscrevem suas marcas - tornam imprescindível a afirmação da coletividade cujo trabalho de pesquisa carrega, referente a uma multiplicidade de afetos e intensidades. Dessa colaboração entre cérebros, uma rede afetiva de encontros me possibilitou traçar essas linhas. E assim os campos, na cartografia, numa perspectiva inventiva, estão sempre sendo reconfigurados, outros trajetos e devires vão surgindo, com direções flutuantes, deixando vazar os sentidos.

Tratava-se, no processo de encontro com as gravações e diários, de contar, narrá-los, mas, além disso, situar-se mais tantas vezes lá. Permitir que se ativasse o que parecia obtuso em um determinado olhar e escuta, deixando isso conversar com a escrita. Que o tempo aparecesse e que uma rede do sensível, do singular, se inventasse, numa experimentação do campo, descobrindo as multiplicidades que o compõem. Parece que se trata sempre de um jogar-se para o vivido, capturando e mesmo inventando os novos signos, ora aparecendo, ora apagando-se, rindo, brincando, dançando com eles.

Tratava-se sempre de explorar esse campo de singularidades: produzir os dados, produzir-se com os dados, colocar-se em plena suscetibilidade a possíveis metamorfoses que os problemas nos violentam (ORLANDI, 1993). Como pousar o olhar em cada um nos encontros afim de que aprendesse com eles? Atentei acentuadamente à contingência do tempo, a fim de que pudesse trazer os acontecimentos, a linguagem dos corpos, à violência do que nos forçava a pensar no encontro com os corpos, "compreender brumas, pestes, vazios, saltos, imobilizações, suspenses, precipitações" (DELEUZE e PARNET, 1998 , p. 108). Nesse exercício, houve perdas, fluxos de signos os quais não se pode captar, redes nas quais não consegui me inserir, a solubilidade que não atingi, de certa incapacidade de uma performance que dissolva o sujeito, que se arraste com 0 acontecimento e suas incongruências.

Ainda, tratava-se (e de novo, sempre se trata) de desenvolver uma atenção, não desinteressada, mas interessada de fato na perspectiva do outro, operando numa saída de uma interioridade do eu, dado como centro de valor. A fundo, esse encontro com o outro vai além das iniciativas de um eu - com base no respeito ou no tolerar o outro mas sobretudo se dá na imposição da alteridade desse outro; sou eu que, em fato, me 
constituo "desses outros" e tenho que abrir caminho, espaço, veias de um lugar que já pertence a eles. Minha fala, meu pensar, minha consciência, linguagem, corpo, signos, já é constitutivo de outros em mim, dimensões tomadas de configurações alheias, do que não nos pertence, na medida em que está exposto ao olhar e à palavra dos outros.

Trago, assim, imagens textuais de alguns dos encontros, na intenção de mostrar, ainda que de forma breve, a atmosfera do acontecimento, junto ao recorte de alguns escritos dos diários pessoais. Os encontros, no trabalho, encontravam-se em forma cronológica com que foram construídos. No entanto, diários e conversas foram sempre jogados para tensionar um modo de leitura cronológico, como afecção ao leitor, tensionando e inventando rupturas. O mesmo com a escrita do trabalho: deixei que algo se desse de inventivo e que a escrita agisse. Procurei atentar a digressões, meios e movimentos. E também criei, divaguei: brinquei e descobri palavras. Quanto de verossímil? Muito, posto que as narrativas do grupo tomaram quase por completo a pesquisa. Mas elas eram burladas, quebradas, raspadas, acentuando olhares, vozes, cores, cheiros, modos, vendo o que talvez não existisse, onde real e imaginário se misturavam desenhando um mapa livre e fabulador, ainda que um mapa muito preso ao que, de fato, passava-se lá.

Eis o fruto do meu ventre. Criatura noturna, do fundo de um poço de águas podres, ele me olha. O que quer de mim? Agora é hora do grande grito, de agarrar com as duas mãos essa coisa nojenta e a rasgar ao meio e jogar os pedaços longe, e acordar, e voltar à minha vida de mulher simples, casta, discreta, que atende sua família, cuida de sua casa, cumpre seus deveres, e nunca, nunca, nunca se maculou. Quem sempre fez tudo direito, como eu, não merece desgraça nem horror. Mas quando vou fazer isso, ele abre abaixo dos olhos uma boquinha também negra, sem dentes, que se abre e fecha como se tivesse sede, ou fome. Então compreendo: o filho do meu pesadelo quer me devorar. Vai começar pelo rosto, arrancando minha carne dos ossos da face, esvaziando meus olhos, sugando minha língua, e por fim me engolindo toda, para que eu para sempre desapareça no inferno de suas entranhas. Então eu, berro, urro, para que ele se assuste e desapareça em poeira de carne e pele e gosma, como aqueles fantasmas. E eu possa acordar e me ver vestida com minha camisola modesta e recatada, debaixo das cobertas gastas, em minha velha cama, minha velha casa, meu velho corpo, a simples e sólida realidade onde me sinto bem. Pois, como me ensinaram desde pequena, se a gente faz tudo certo e cumpre as tarefas todas, nada de verdadeiramente mau pode nos acontecer. O bem sempre vence, o céu é mais poderoso do que os infernos. Deus é bom (O silêncio dos Amantes, Lya Luft). 
Silêncio, paralisia no olhar, inexatidão da postura. A curiosidade enebria os instantes seguidos produzidos pela voz grave, ininterrupta, veloz e segura de SÁ. Na sequência da leitura do conto, os colegas a fitam com semblante informe e surpreso e que, ao longo da escuta, circula na atmosfera da indisposição. Olhos baixos que se levantam, procurando-a. A cabeça se move, como quem pensa sobre o que ouve, e levanta. Carregados por sua voz, permanecem assim durante quase todo o conto lido. Todos, embalados por SÁ, movidos pelo estranhamento, incontrolados por alguma coisa, lançam no meio da sala algo indecifrável.

Quando termina, sorrio, não sabendo até então o que eles falariam, mas não me surpreendo com os comentários assustados sobre o recorte do livro. Mas comecei aí a perceber a falta da entonação alegre nos trechos e livros escolhidos por mim. Mas me surpreendo de novo, por ainda não ver problema nisso.

- O que te provocou ler isso?, pergunto a ela.

- Ai, eu não gostei muito, aquela parte quando nasce a criatura e ela vai subindo por ela; na verdade é... o corpo dela mostrando tudo aquilo que ela sempre reprimiu, que fizeram ela reprimir, né? E daí também fala daquela parte que o pai dela ensinava ela se reprimir, que o pai dela ensinava que tudo era pesadelo e que ela ia acordar, que ela podia fugir dos medos. Então, essa gravidez é quando ela não consegue mais fugir de tudo que ela esconde, daí nasce... aquele mau [bebê] quer devorar ela. Pelo menos foi isso o que eu entendi.

Os segundos de silêncio, os segundos de silêncio(s)...os segundos. Silêncio.

- Podem falar pessoal. (impera SÁ)

Apoio-me na mesa, esperando o que que pode vir ainda dos outros.

- É um texto de terror isso, né?, rompe ZÉ, rindo-se.

- Eu imaginei toda cena (SOL).

- Eu achei que tudo isso era imaginação dela, que ela não queria o nenê, diz MI.

Procuravam entender o que se passara com a personagem do conto: o bebê, o parto, o texto que parecia um filme de terror; se era delírio da personagem, se ela viveu realmente a gravidez e o parto.

- Às vezes tem que ler duas ou três vezes pra entender o que ela [Lya] tá dizendo, afirma VAL. 
Não se estendem, não se arriscam. Pairara no ar aquela narrativa, incógnita, deixando o peso de não se poder traduzir parte dele. SÁ mexe em seu brinco e ri, olhando para os colegas. DÓ escreve, não vociferando sua opinião diante da história. Eu espero, e espero... (e me noto em esperas). Silêncios; o silêncio que fui descobrindo como irresoluto e carregado de coisas, coisas das quais não sabia lidar. Voltam. Então, alguém faz riso do susto, do que o mórbido faz rir: brincam e riem ainda quanto ao teor assustador do texto.

- Bom de ler antes de dormir (DÓ).

Desligar-se da última leitura. Sinto o incômodo e desejo de mudar de texto, e convido alguém para continuar a roda. Saliento, no entanto, o encontro com a escrita de SÁ em seu diário, onde rabisca:

O texto é angustiante, causa uma aflição, de uma pessoa que se reprime e é oprimida por os que estão em volta e quer encontrar maneiras de passar por cima disso, como na citação do pai dela. E isso vai se acumulando durante anos até o momento de que isso não é mais suportável e "começa a tomar corpo" até que isso vem à tona e ela reconhece isso, mas mesmo assim ela tem medo de encarar a verdade e tudo que ela tanto fez para esconder em um lugar que nem ela percebia que ali estava. Às vezes a verdade e tudo aquilo que nos machuca é tão difícil de se conviver que escondemos até que o desconforto é tão grande que mesmo não querendo temos que encarar, e isso é doloroso, mudar, perceber é sim doloroso. E a vontade de querer voltar para onde é cômodo, mesmo que depois de encarar os problemas, isso não seja capaz de acontecer, mesmo que não resolva os medos, não os supere, é impossível.

\section{Socorro!}

Não estou sentindo nada

Nem medo, nem calor, nem fogo

Não vai dar mais pra chorar

Nem pra rir...

Socorro!

Alguma alma mesmo que penada 
Me empreste suas penas

Já não sinto amor, nem dor

Já não sinto nada...

\section{Socorro!}

Alguém me dê um coração

Que esse já não bate nem apanha

Por favor!

Uma emoção pequena, qualquer coisa!

Qualquer coisa que se sinta...

Tem tantos sentimentos

Deve ter algum que sirva

Qualquer coisa que se sinta

Tem tantos sentimentos

Deve ter algum que sirva.

Enquanto ecoa, DE rabiscava, desenhava em seu diário amarelo. CÁ e MI escrevem também nos seus. Os outros escutam...seus corpos pareciam mais relaxados, com expressões menos enrijecidas. Alguns segundos, e CÉ também escreve. LA encosta a cabeça na parede e a balança, dançando com a música. ZÉ, que não estava encostado à parede, dobrara as pernas e apoiara a cabeça sob suas mãos. RÉ, com as pernas cruzadas, fecha seus braços e põe sua cabeça entre elas, escondendo o rosto. SOL, com seu rosto sereno, expõe um leve sorriso ao canto da boca e rabisca alguma coisa num papel. FA fecha os olhos e SI, ao seu lado, escreve sob suas pernas, flexionadas. As variações dos corpos eram mínimas ao longo dos quase 4 minutos de música. Não havia ruídos, conversas, e os mínimos movimentos e gestos davam a impressão de um tempo que parava de correr. Ele estagnava, mas seus pensamentos não...e ninguém sabia por onde eles estariam e com que velocidades e lentidões eram produzidos.

A música termina e CÁ perguntara à AL se não haveria mais música. Ela responde que sim, mas faz um intervalo de tempo entre uma e outra, na esperança de que houvesse comentários. RÉ, então, afirmara que adorava a música Socorro, e que sempre a ouvia na voz da cantora Cássia Eller.

- Ficava horas viajando ouvindo essa música. Sabe aquilo, repete...repete...repete! Eu acho bem bonita essa música. E ele fala muito da falta de sentimento, só que eu acho que ele tem um sentimento ali: é a falta do sentimento que ele tem porque ele quer uma ajuda e isso já é um sentimento. Já é uma angústia porque tu não tá sentindo nada. Daí 
dá pra ver de várias formas também, né? O que te incomoda, aquela agonia nos incomodando, é porque alguma coisa tem que ser feita... Alguma coisa tu tem que mudar... um sentimento pra ti fazer uma mudança... pra ti ir pra um lado.

- Algo que sirva, né, acrescenta SOL.

- Pra ti pegar um caminho... é, algo que sirva pra ti fazer alguma coisa, afirma RÉ, olhando para SOL.

A música de Arnaldo foi a que mais apareceu nos diários. A frase qualquer coisa que se sinta. Tem tanto sentimento, deve ter algum que sirva, foi escrita em muitos deles. Me provocou uma sensação boa ao contrário dos poemas dele, escreve CÉ. Como havia me perdido no silêncio deles, transitava entre continuar com as músicas, colocar outros poemas que não estavam "no roteiro", esperar que falassem, e, assim, o tempo era sentido como um espaço entre as composições que ia colocando. Era nesse tempo quase que vazio, mas cheio de signos e intensidade, que alguns olhares se cruzavam ou os colegas balbuciavam algumas coisas entre eles. Virava-revirava-virava as páginas do diário, torcendo para encontrar o que procurava. Já não sabia mais em que CD estava o quê e DEI, na postura de me observar, e aguardando o prosseguimento da aula, deixavame ainda mais angustiada. Eles percebem meu desconcerto ao "sair do programado", a representação da insegurança e do controlar o viver ali, estampados em sua frente. SÁ, acometendo-se do meu embaraço, ri, o que me deixa mais perdida. Todos esperavam de mim a continuidade do não-silêncio, do espaço-tempo preenchido por alguma coisa que não fosse aquilo. E assim permaneço, por longos segundos, procurando a faixa musical: vou passando uma por uma, com uma vaga lembrança onde havia gravado o quê, já que tudo o que planejara para aquele encontro havia se esgotado. Depois da interminável circunstância aflitiva, apegada ao olhar dos outros sobre mim, na dificuldade de produzir um corpo desenvolto pelo acaso, ponho a tocar a crônica $A$ Surpresa, de Clarice Lispector.

Tudo ao contrário. Eu sinto tudo. Tudo demais. Tanta coisa que não sinto tudo direito, são partes, emoções em partes. Às vezes inteiras, às vezes aquelas que não querem ser sentidas. É melhor sentir nada ou tudo? Também, precisa até isso ter um padrão? Uma regra? O que importa, creio eu, são as consequências dos sentimentos. Todos fazem falta. O mundo é frio, mas eu não me considero, pelo contrário. Tomo as dores dos outros, fico triste se a aula não funciona, se os alunos vão mal na prova, se não fazem os trabalhos direito. Acho que todo professor é assim: se importa mais com o aprendizado dos alunos do que eles mesmos, sendo que a vida e o aprendizado é deles. "A gente 
ensina o que a gente é". Interessante. E agora, para por mais uma interrogação na minha cabeça, o tempo. Vivo brigado com o tempo. Com o tempo que faltou na aula, no entendimento, no meu sono, no lazer. Mas essas são as minhas escolhas. (Diário de Cá)

\section{A invenção que levou além}

Do tesouro oculto que todos carregamos: a possibilidade de inventar-se. Das relações que nos constituem e que constituímos no entrevaguear dos campos de efetuação da vida, as forças lançadas e efetivadas a partir da composição, cooperação e engendramento com outras forças, nos colocam em comunicação, e nos reinventam, nos modificam. Entra nisso tudo o sentir, o que nos liga uns aos outros: aprender, e produzir conhecimento, por experiências de problematização.

A combinação, interferência, colaboração entre uma multiplicidade de ideias, conceitos, hábitos, comportamentos, percepções, sensações. E essa invenção abordada corresponde a uma ação que suspende dentro do indivíduo ou dentro da sociedade aquilo que já está individuado, que já se tornou habitual: "a invenção é um processo de criação de diferença que coloca em xeque, a cada vez, o ser em sua individuação" (LAZZARATO, 2006, p.46).

Isso é aprender. E quis aqui trazer um pouco desse experimentar de uma pesquisa que se apresenta como próprio processo de aprender, um caminho como campo de possibilidades de pensar, de criar, de sentir, de viver e que não se preocupa com que isso irrompa na escrita.

Inventamos um tempo e compartilhamos sentires, não autorizado no tempo da identidade, do demasiado humano e idealizado da educação. Continuidade e descontinuidade de fluxos, revelando as múltiplas singularidades que um espaço formativo abarca. Os silêncios, gestos, mínimos e invisíveis atos que tem como movimento a fuga de papéis e de funções pré-definidas. Era a desconstituição de sujeitos tomados como entidades acabadas, para aparecer a emergência do que é múltiplo, conjunto, compartilhado. Modificamo-nos uns aos outros, porque a interpenetração de elementos, coisas e nomes próprios deixou de percebermo-nos uns exteriores aos outros. Produzimos nossa temporalidade e espaço, agindo uns sobre os outros, na interpenetração de mentes e corpos, concentrando os mundos possíveis que carregamos. Mas o que explano aqui não é para resultar a pesquisa numa finalidade, utilidade, num resultado e lugar de chegada. Trago para fazer sentir no que ela consistiu enquanto possibilidade, enquanto processo, sempre mutante e ininterruptamente aberta ao acaso e suas metamorfoses. 
De todos os pequenos passos, das contradições da pesquisa, de uma pesquisa que segue junto à vida, em meio a ela. Que os espaços da vida possam ser preenchidos mesmo de vazio e silêncio, estes onde parece que reside o estranhamento e onde o aprender se dá. Estamos impregnados de outros, outros de nós, devires sem nome. Mas há tão pouco desses outros, e acessos dos outros em nós nos lugares e tempos que chamamos de formativos, entre eles os da pesquisa. Tanta ausência e negação daquilo que é inerente ao estar vivo, que é mudar, durar, encarregar-se dos desejos que nos atropelam e nos fazem caminhar, em educação. Dos excessos e lacunas dessa pesquisa-vida, das alegrias que a escrita produziu, do que ela teve que abortar: que esteja tudo conectado ao que de fato se pode e se deseja num lugar sai um pouco das formas, que (des)forme. Dos acontecimentos cotidianos que se tornam grandiosos dentro da rotina cristalizada, pueril e jogada ao campo da culpa, da inutilidade, da desavença, do peso, da arrogância, e da paralisia, do negar o que nos faz vivos.

Uma pesquisa que se constrói no apagar-se, diluir-se. Que se deseja esquecer num movimento de escrita, para tentar ser outro(s). Desobedecer, deixar que as coisas tomem outros rumos para inventar um trabalho que não permita fechar-se em si mesmo. Um trabalho que trate de inventar-se, de fazer a pele sentir as coisas de outro jeito, estendendo seu perfil a ficar informe, esperando que outros contornos o modifiquem, de novo. Inventar desejos, descobrir uma potência escondida, um resquício de possíveis, de diferenciações e singularidades. Deixar ouvir o que grita e, no inaudível som do mundo, compor linguagens variadas na descoberta de outras pesquisas em meio a uma pesquisa primeira.

Porque se trata de um trabalho investigativo que toma a invenção como caminhar, como metodologia? Porque inventávamos problemas, todos nós: grupos de estudantes de mestrado, de pesquisa, de orientação, e grupo das quartas-feiras, onde todos estávamos juntos. Enquanto membro do grupo, elegi tensores para produzir o movimento onde faria a cognição divergir, bifurcar, mesmo que temporariamente os estudantes buscassem "respostas" ou quisessem "resolver" o que se passava com a angústia que reverberava após os Encontros. Todos produzem algo, ao fazer a cognição divergir?, pode alguém indagar-se. Penso que não, e isso em momento algum pode e deseja, aqui, ser afirmado. Funcionávamos como provocadores, inventando problemas, colocando a cognição em devir (em nós e com eles), mas a abertura ao devir por vezes não produz outros/novos planos de sentido, de mundos, de novas relações com ele. Qualquer coisa pode ser desencadeadora de problemas, correlato de uma cognição divergente e bifurcante: "o devir da cognição surge como uma suspensão da ação, ocorrendo num instante em que não fazemos senão dignificar o comum, torná-lo incomum" (KASTRUP, 2007a, p. 235). Mas esse devir não é, por si só, inventivo. Ele abre, encaminha o processo de invenção, o 
que chamamos sempre de produção de novas subjetividades, porque precisa causar ressonância e envolver um trato com aquilo que nos fez abandonar um modo de pensar, um modo de agir, um modo de vida. Um pouco sobre aprender a desaprender.

Novas/outras formas de produzir uma pesquisa. Por isso, o trabalho - e estendo para este artigo - intenta em ser tomado como descoberta de uma pesquisa-escrita coletiva. Mas ele passa por corpos que silenciam marcas, afugentam desassossegos, creem na exatidão e atravessam um deserto povoado de ideais; corpos que não navegam, não se experimentam, não se permitem esvaziar, lançar-se ao estranho; corpos que carregam sombras, sombras-fardos, cheios de melancolia, absortos no silêncio da vida; mas também - e principalmente - corpos proliferantes, múltiplos e intensos, e foram estes que tiveram campo de efetuação de aparecer na pesquisa. Nesses investimentos é que reside a pulsão de tantas outras coisas, tantas ainda por vir. Somos, de saída, inventivos. Foi nisso que esta pesquisa apostou. Tempo verbal presente: tem apostado, em espaços e tempos em educação.

\section{Referências}

CABRAL, M. C. C. Encontros que nos movem: a leitura como experiência inventiva. 2006. 174p. Tese (Doutorado em Psicologia). Universidade Federal do Rio de Janeiro, Rio de Janeiro. 2006.

CABRAL, M. C. C; KASTRUP, V. Leitura de acolhimento: uma experiência de devir consciente. Psicologia: Reflexão e Crítica, Porto Alegre, v. 22, n. 2. 2009. Disponível em: $\quad<$ http://www.scielo.br/scielo.php?script=sci_arttext\&pid=S010279722009000200016\&lng=en\&nrm=iso >. Acesso em: 08/05/2014.

DELEUZE, G. Espinosa: filosofia prática. São Paulo: Escuta, 2002. 144 p.

Proust e os signos. São Paulo: Forense Universitária, 2006, 174 p.

A lógica da sensação. Rio de Janeiro: Jorge Zahar, 2007, 183 p.

DELEUZE, G; PARNET, C. Diálogos. São Paulo: Escuta, 1998. 184 p.

DE-NARDIN, M. H.; SORDI, R. O. Um estudo sobre as formas de atenção na sala de aula e suas implicações para a aprendizagem. Psicologia e Sociedade, v. 19, n. 1, p.99106, abr. 2007. Disponível em: <http://www.scielo.br/scielo.php?script=sci_arttext\&pid=S010271822007000100014\&/n $\mathrm{g}=\mathrm{en \& nrm}=$ iso $>$. Acesso em 02/05/2014. 
GUATTARI, F. As três ecologias. Campinas: Papirus, 1990, 56 p.

KASTRUP, V. O devir-criança e a cognição contemporânea. Psicologia: Reflexão e Crítica, Porto Alegre, v. 13, n. 3, 2000.

Aprendizagem, arte e invenção. Psicologia em estudo. Maringá, v. 6, n. 1,

p.17-27, jan-jun. 2001. Disponível em <http://www.scielo.br/scielo.php?script=sci_arttext\&pid=S141373722001000100003\&ln $\mathrm{g}=\mathrm{pt \& nrm}=$ iso $>$. Acesso em: 05/06/2010.

A rede: uma figura empírica da ontologia do presente. In: FONSECA, T. M. G. \& KIRST, P. G. (Orgs.), Cartografia e devires: a construção do presente. Porto Alegre: UFRGS, 2003, p. 53-62.

A aprendizagem da atenção na cognição inventiva. Psicologia \& Sociedade, v.16, n. 3, p. 7-16. 2004. Disponível em: <http://www.scielo.br/pdf/psoc/v16n3/a02v16n3>. Acesso em: 02/05/2014.

Políticas cognitivas na formação do professor e o problema do devir-mestre.

Educação Social, v. 26, n. 93, p. 1273-1288. 2005a. Disponível em: <http://www.scielo.br/pdf/es/v26n93/27279.pdf>. Acesso em: 02/05/2014.

O devir-consciente em rodas de poesia. Revista do Departamento de

Psicologia. Universidade Federal Fluminense, v 17, n. 2, p. 45-60, jul-dez. 2005b. Disponível em: <http://www.scielo.br/pdf/rdpsi/v17n2/v17n2a05.pdf>. Acesso em: 02/05/2014.

A invenção de si e do mundo: uma introdução do tempo e do coletivo no estudo da cognição. Belo Horizonte: Autêntica, 2007a. 256 p.

. O funcionamento da atenção no trabalho do cartógrafo. Psicologia e Sociedade. Universidade Federal de Rio de Janeiro, v. 19, n. 1, p. 15-22, jan-abr, 2007b. Disponível em: <http://www.scielo.br/pdf/psoc/v19n1/a03v19n1>. Acesso em: 28/04/2014.

KIRST, P. G.; Giacomel, A. E.; Ribeiro, C. J. S; COSTA, L. A. C.; ANDReOli, G. S. Conhecimento e cartografia: tempestades de possíveis. In: FONSECA, T. M. G. \& KIRST, P. G. (Orgs.). Cartografia e devires: a construção do presente. Porto Alegre, Editora da UFRGS, 2003, p. 91-101.

LAZZARATO, M. As revoluções do capitalismo: a política do império. Rio de Janeiro: Civilização brasileira, 2006. 268 p. 
LUFT, L. O silêncio dos amantes. Rio de Janeiro: Record, 2008. 160p.

MAIRESSE, D. Cartografia: do método à arte de fazer pesquisa. In: FONSECA, T. M. G. \& KIRST, P. G. (Orgs.). Cartografia e devires: a construção do presente. Porto Alegre, Editora da UFRGS, 2003, p. 259-271.

ORLANDI, L. B. O indivíduo e sua implexa pré-individualidade. In: 0 reencantamento do concreto. Cadernos de subjetividade/ Núcleo de Estudos e Pesquisas da Subjetividade do Programa de Pós-Graduados em Psicologia Clínica da PUC-SP, v. 1, no 1, São Paulo, 1993.

RAMÃO, S. R.; MENEGHEL, S. N.; OLIVEIRA, C. Nos caminhos de Iansã: cartografando a subjetividade de mulheres em situação de violência de gênero. Psicologia \& Sociedade, v. 17, n. 2, p. 79-87. 2005. Disponível em: http://dx.doi.org/10.1590/S0102-71822005000200011. Acesso em: 10/09/2011.

ROMAGNOLI, R. C. A cartografia e a relação pesquisa e vida. Psicologia e Sociedade, v. 21, n. 2, p. 166-173. 2009. Disponível em: http://dx.doi.org/10.1590/S010271822009000200003. Acesso em: 13/01/2011.

SORDI, R. O.; DE-NARDIN, M. H. Contribuições de Francisco Varela ao estudo da aprendizagem inventiva em sala de aula. Informática na educação: teoria e prática, v.12, n. 2, p. 82-92, 2009. Disponível em: $<$ http://seer.ufrgs.br/index.php/InfEducTeoriaPratica/article/view/9918/7245 >. Acesso em: 02/05/2014. 
Alice Copetti Dalmaso (UFSM/RS)

Bacharel e Licenciada em Ciências Biológicas pela Universidade Federal de Santa Maria (2005-2009). Mestre em Educação pela mesma instituição (2013), atuando na Linha de Pesquisa Formação, Saberes e Desenvolvimento Profissional com ênfase na temática de Processos de Subjetivação na Formação Inicial de Professores. Atualmente é Doutoranda em Educação, na Linha de Pesquisa LP4-Educação e Artes (2013-atual), PPGE/UFSM. Membro do GEPAEC - Grupo de Estudos e Pesquisas em Arte, Educação e Cultura da UFSM, desenvolvendo pesquisas junto ao mesmo sobre as temáticas de Literatura, Leitura e Escrita como processos formativos. Endereço institucional: Av. Roraima, no 1000, Prédio 16 - Centro de Educação. Laboratório de Artes Visuais (LAV) - Sala 3366. Cidade Universitária - Campus Bairro Camobi. Santa Maria-RS, CEP 97105-900. Endereço eletrônico: alicedalmaso@gmail gmail.com

Recebido em: 25/07/2014

Aprovado em: 08/08/2014 